\title{
PRESSURE FLUCTUATION PROPAGATES IN PHREATIC AQUIFERS
}

\author{
Jet-Chau Wen ${ }^{1}$, Ray-Shyan $\mathrm{Wu}^{2}$ and Jyh-Horng Wen ${ }^{3}$ \\ ${ }^{1}$ Depart. of Civil Engineering, Chung-Yuan Christian University, Chung-Li, Taiwan 32023, R. O. C. \\ ${ }^{2}$ Depart. of Civil Engineering, National Central University, Chung-Li, Taiwan 32054, R. O. C. \\ ${ }^{3}$ Depart. of Civil Engineering, National Chung Cheng University, Ming-Shiung, Chia-Yi, Taiwan, R. O. C.
}

\section{ABSTRACT}

The purpose of this study is to develop a numerical model to simulate the behavior of the head potential fluctuation in subsurface flow. Numerical and analytical solutions are presented. Impacts of the storativity and porosity on the head potential fluctuation are investigated in this paper. It is found, in onedimensional subsurface flow, that the less the storativity, the easier the fluctuation of the head potential propagates. In addition, an asymptotic behavior of the head fluctuation does not reach until the head propagation travels more than 0.75 times the total aquifer length.

\section{INTRODUCTION}

The stochastic process has been used in heterogeneous subsurface hydrological analysis for two decades. Spectral density theory and perturbed method to differential equation with stochastic input parameters and deriving the solutions were applied in the approaches (Gelhar 1974, Bakr 1976, Gelhar 1976, Bakr et al. 1978, Gujtahar et al. 1978, Gelhar 1986, Marschall 1989). Most of researches stemmed from the spectrum of lognormal distribution of hydraulic conductivity (Bakr 1976, Gelhar 1976, Bakr et al. 1978, Gujtahar et al. 1978, Gelhar 1986). For temporal variables of subsurface flow, the variation of groundwater level may changed at monthly (or seasonal) frequencies. It is common to focus on the quasi-steady-state of the variation rather than to explore its detailed unsteady response (Gelhar, 1993). However, dynamic response of subsurface-flow systems may have a significant amount of information about the nature of the flow system. This is the purpose of this paper to investigate the impact of the storativity on the flow system.

A numerical simulation model with finite element method for the impact of the storativity is applied in this paper. Two one-dimensional subsurface phreatic aquifer system will be investigated. The input parameters are water table of subsurface and the conjunct stream which has fluctuation, the transmissivity (or hydraulic conductivity) and porosity which are treated in deterministics. One of these two systems is the same as the one in Gelhar (1974), which will be compared to our numerical result. This case considers the water table propagation of subsurface due to the fluctuation of stream (a constant head boundary condition). Normalized spectral density function of the head potential will be applied to perform the fluctuation behavior of the head potential. The second system is analyzed in a vertical phreatic aquifer (leakage bottom and impervious in both lateral). The investigation of this vertical flow system will involve the analytical and numerical solutions.

\section{MATHEMATICAL DEVELOPMENT} 1972):

The continuity equation in a general form for unsteady-state subsurface flow can be described as (Bear,

$$
s \frac{\partial \mathrm{h}}{\partial \mathrm{t}}=\mathrm{K} \nabla^{2} \mathrm{~h}+\mathrm{q}
$$

where s denotes the specific storativity; $\mathrm{K}$ represents the hydraulic conductivity; $\nabla^{2}$ is the Laplace operator; $\mathrm{h}$ denotes the Hubbert's potential(a function of position and time); q represents sink or source term (a function of position and time). 
The boundary conditions are three types in general for equation (1) and are written as:

1. potential boundary condition:

$$
\mathrm{h}(\Gamma)=\mathrm{H}(\mathrm{t})
$$

2. no-flow boundary condition:

$$
\frac{\partial}{\partial \mathrm{n}} \mathrm{h}\left(\Gamma_{1}\right)=0
$$

3. linearized free-surface boundary condition:

$$
\mathrm{K} \frac{\partial \mathrm{h}}{\partial \mathrm{n}}+\mathrm{n} \frac{\partial \mathrm{h}}{\partial \mathrm{t}}=\varepsilon
$$

where $\mathrm{n}$ represents the effective porosity of phreatic aquifer and $\varepsilon$ represents the infiltration rate in the saturated aquifer.

Stochastic Differential Equation for Transient Flow in

Phreatic Aquifer--Cross-Sectional Model

By using the first-order perturbation method for the potential and singularity terms, $\mathrm{h}$ and $\mathrm{q}$ are described as:

$$
h(\vec{x}, t)=\bar{h}(\vec{x})+h^{\prime}(\vec{x}, t) \text { and } q(\vec{x}, t)=\bar{q}(\vec{x})+q^{\prime}(\vec{x}, t)
$$

where $\bar{h}$ and $\bar{q}$ are the means of $h$ and $q$, respectively, $h^{\prime}$ and $q^{\prime}$ are the perturbations of $h$ and $q$, respectively, and $\vec{x}$ represents a position vector. Substituting equation (5) into equation (1) leads to

$$
s \frac{\partial \overline{\mathrm{h}}}{\partial \mathrm{t}}+s \frac{\partial \mathrm{h}^{\prime}}{\partial \mathrm{t}}=\mathrm{K} \nabla^{2} \overline{\mathrm{h}}+\mathrm{K} \nabla^{2} \mathrm{~h}^{\prime}+\overline{\mathrm{q}}+\mathrm{q}^{\prime}
$$

Since the perturbations of $\mathrm{h}$ and $\mathrm{q}$ are zero mean, equation (6) is rewritten by taking mean of it as:

$$
s \frac{\partial \overline{\mathrm{h}}}{\partial \mathrm{t}}=\mathrm{K} \nabla^{2} \overline{\mathrm{h}}+\overline{\mathrm{q}}
$$

Subtracting equation (7) by equation (6),leads to:

$$
s \frac{\partial h^{\prime}}{\partial t}=K \nabla^{2} h^{\prime}+q^{\prime}
$$

Equation (8) is known as the stochastic differential equation of the continuity equation. In this study, we will focus on analyzing the behavior of the head perturbation in one-dimensional and two-dimensional aquifers.

Using the Fourier-Stieltjes Transform for these perturbations of $\mathrm{h}$ and $\mathrm{q}$ leads to:

$$
h^{\prime}(x, y, t)=\int_{-\infty}^{\infty} \exp (i \omega t) d Z_{h}(x, y, \omega) \text { and } q^{\prime}(x, y, t)=\int_{-\infty}^{\infty} \exp (i \omega t) d Z_{q}(x, y, \omega)
$$

Substituting equation (9) into equation (8), a generalized amplitude equation is obtained:

$$
\nabla(\mathrm{K} \nabla \mathrm{dZ})-s \omega i \mathrm{Z}_{\mathrm{h}}+\mathrm{dZ}_{\mathrm{q}}=0
$$

where $\mathrm{dZ}$ represents a complex Fourier amplitude that can be expressed in terms of the real and imaginary parts:

$$
\mathrm{dZ}_{\mathrm{h}}=\phi_{\mathrm{r}}+\mathrm{i} \phi_{\mathrm{i}} \text { and } \mathrm{dZ}_{\mathrm{q}}=\psi_{\mathrm{r}}+\mathrm{i} \psi_{\mathrm{i}}
$$

Replacing equation (11) for equation (10), we obtain two equations, one for the real part and one for the imaginary part of the Fourier amplitude:

$$
\begin{aligned}
& \nabla\left(\mathrm{K} \nabla \phi_{\mathrm{r}}\right)+s \omega \phi_{\mathrm{i}}+\psi_{\mathrm{r}}=0 \\
& \nabla\left(\mathrm{K} \nabla \phi_{\mathrm{i}}\right)-s \omega \phi_{\mathrm{r}}+\psi_{\mathrm{i}}=0
\end{aligned}
$$

where $\phi_{\mathrm{r}}$ and $\phi_{\mathrm{i}}$ are the real and imaginary parts of $\mathrm{dZ}$. These two equations have to be simultaneously solved corresponding to their appropriate boundary conditions. The boundary conditions shown in equations (2), (3), and (4), therefore, need to be transform into the frequency domain.

In most cases, the solution of equations (12) and (13) require using numerical method. In this study, we apply the Finite Element Method to solve these two equations.

Finite Element Approximation 
The standard quadrilateral element is used for this study. The approximation of $\mathrm{dZ}_{\mathrm{h}}$ and $\mathrm{dZ}_{\mathrm{q}}$ in each element is given by:

$$
f(x, y) \cong \sum_{i=1}^{N_{e}} N_{i}(x, y) f_{i}
$$

where $N_{i}(x, y)=$ shape functions, $f_{i}=$ the value of function $f(x, y)$ at node $i$. Applying the weighted residual method to equation (12), using the appropriate boundary conditions, and then discretizing, we obtain a set of finite element equations.

$$
\begin{gathered}
{[\mathrm{A}]\left\{\phi_{\mathrm{r}}\right\}+[\mathrm{B}]\left\{\phi_{\mathrm{i}}\right\}=\{\mathrm{C}\}} \\
\text { where } \mathrm{A}_{\mathrm{ij}}=\iint \mathrm{K}\left(\frac{\partial \mathrm{N}_{\mathrm{i}} \partial \mathrm{N}_{\mathrm{j}}}{\partial \mathrm{x} \partial \mathrm{x}}+\frac{\partial \mathrm{N}_{\mathrm{i}} \partial \mathrm{N}_{\mathrm{j}}}{\partial \mathrm{y} \partial \mathrm{y}}\right) \mathrm{d} \Omega ; \mathrm{B}_{\mathrm{ij}}=\iint s \omega \mathrm{N}_{\mathrm{i}} \mathrm{N}_{\mathrm{j}} \mathrm{d} \Omega+\int_{\Gamma} n \omega \mathrm{N}_{\mathrm{i}} \mathrm{N}_{\mathrm{j}} \mathrm{d} \Gamma \\
\text { and } \mathrm{C}_{\mathrm{i}}=-\sum_{\mathrm{j}} \int_{\Gamma} \mathrm{N}_{\mathrm{i}} \mathrm{N}_{\mathrm{j}} \varepsilon_{\mathrm{r}} \mathrm{d} \Gamma-\iint \mathrm{N}_{\mathrm{j}} \psi_{\mathrm{r}} \mathrm{d} \Omega .
\end{gathered}
$$

Similarly, for equation (13) we obtain:

$$
[D]\left\{\phi_{\mathrm{r}}\right\}+[\mathrm{E}]\left\{\phi_{\mathrm{i}}\right\}=\{\mathrm{F}\}
$$

$$
\text { where: } D_{i j}=-B_{i j} ; E_{i j}=A_{i j} ; \text { and } F_{i}=-\sum_{j} \int_{\Gamma} N_{i} N_{j} \varepsilon_{i} d \Gamma-\iint N_{j} \psi_{i} d \Omega \text {. }
$$

From equation (15) to (16), a program for this finite element approximation can be finished.

\section{Horizontal Flow Case}

\section{CASE STUDIES: ONE-DIMENSIONAL FLOW PROBLEMS}

In this case, we consider a phreatic aquifer with impervious bottom which is conjunct to a stream with constant head. Because it is parallel to the river in a plane view, this problem can be reduced to one-dimensional problem by adopting the Dupuit assumption, as shown in Fig. 1. The motivation of this problem is to check the horizontal flow case. The saturated thickness of this phreatic aquifer is assumed to be constant. Consequently, the transmissivity is dealt with a constant as the hydraulic conductivity is homogeneous in this whole aquifer. The governing equation for this horizontal flow problem is described as $\left(\mathrm{h}-\mathrm{h}_{0}<<\mathrm{h}_{0}\right)$ :

$$
\mathrm{s} \frac{\partial \mathrm{h}}{\partial \mathrm{t}}=\mathrm{T} \frac{\partial^{2} \mathrm{~h}}{\partial \mathrm{x}^{2}}
$$

where $\mathrm{h}(\mathrm{x}, \mathrm{t})$ represents the Hubbert's potential in the phreatic aquifer; $\mathrm{x}$ denotes the horizontal position; $\mathrm{s}$ is the aquifer storativity; $\mathrm{T}$ denotes the transmissivity; $\mathrm{K}$ represents the hydraulic conductivity; $\mathrm{L}$ is the aquifer total length in horizontal direction; $\mathrm{H}(\mathrm{t})$ denotes the river stage (a function of time); $\mathrm{h}_{\mathrm{O}}$ represents the river stage in steady state. The boundary conditions for equation (17) can be expressed as:

$$
\mathrm{x}=0, \quad \mathrm{~h}=\mathrm{h}_{0} ; \quad \mathrm{x}=\mathrm{L}, \quad \frac{\partial \mathrm{h}}{\partial \mathrm{x}}=0
$$

With the same deriving procedure as used in the stochastic differential equation for transient flow, we got an ordinary differential equation of the amplitude equation for head perturbations,

the transformed boundary conditions for equation (19) are

$$
T d " z_{h}-(i \omega s) d z_{h}=0
$$

$$
\mathrm{x}=0, \mathrm{~h}^{\prime}=\mathrm{H}^{\prime}, \mathrm{dz}_{\mathrm{h}}=\mathrm{dz} \mathrm{z}_{\mathrm{H}} ; \mathrm{x}=\mathrm{L}, \frac{\partial \mathrm{h}^{\prime}}{\partial \mathrm{x}}=0, \frac{\mathrm{d}\left(\mathrm{dz}_{\mathrm{h}}\right)}{\mathrm{dx}}=0
$$

Since $\omega$ is valid in the range of $(\infty,-\infty)$, equation (19) has to be solved for $\omega \geq 0$, and $\omega<0$ as:

where $F(\omega, x)=\frac{\cosh [b(x-L)]}{\cosh (b L)}$ and $b=\sqrt{\frac{\omega S}{2 T}}(1+i)$.

$$
\mathrm{dz}_{\mathrm{h}}=\mathrm{F}(\omega, \mathrm{x}) \mathrm{dz_{ \textrm {h } }}
$$

Using the spectral theorem (Gelhar 1974) leads to: 


$$
\mathrm{S}_{\mathrm{hh}}=\mathrm{F} \mathrm{F}^{*} \mathrm{~S}_{\mathrm{HH}}
$$

where $\mathrm{F}^{*}$ is the conjugate function of $\mathrm{F}$. We can, therefore, define a normalized spectral density function, of head potential $\mathrm{S}_{\mathrm{hh}} / \mathrm{S}_{\mathrm{HH}}$, as

$$
\frac{\mathrm{S}_{\mathrm{hh}}}{\mathrm{S}_{\mathrm{HH}}}=\mathrm{FF}^{*}=\frac{\cosh \left[2\left(\frac{\Omega}{2}\right)^{0.5}\left(\frac{\mathrm{X}}{\mathrm{L}}-1\right)\right]+\cos \left[2\left(\frac{\Omega}{2}\right)^{0.5}\left(\frac{\mathrm{X}}{\mathrm{L}}-1\right)\right]}{\cosh \left[2\left(\frac{\Omega}{2}\right)^{0.5}\right]+\cos \left[2\left(\frac{\Omega}{2}\right)^{0.5}\right]}
$$

where $\Omega=\omega * \mathrm{~L} * \mathrm{~L} * \mathrm{~S} / \mathrm{T}$. Equation (23) represents the normalized spectral density function of Hubbert's potential of this horizontal flow case. For comparing the numerical result of the finite element approximation to equation (23), we need to assign values for those input parameters, $\mathrm{L}, \mathrm{T}$, and $\mathrm{s}$, as:

$$
\mathrm{L}=5000 . \mathrm{ft}, \quad \mathrm{T}=10000 . \mathrm{ft}^{2} / \text { year, } \quad \mathrm{s}=0.002
$$

Fig. 2 depicts the results of the finite element approximation and of equation (23). It is found that the normalized spectral density function of the Hubbert's potential in this aquifer decreases as the dimensionless frequency increases under a fixed distance from the river. It is apparent that the fluctuation of the Hubbert's potential in this aquifer is influenced by the river stage. Therefore, the spectral density function of the Hubbert's potential at the river side is equal to the spectral density function of the river stage and then decreases at the larger distance from the river side. Finally, the fluctuation of the Hubbert's potential at this aquifer approximates zero at the impervious boundary $(\mathrm{X}=\mathrm{L})$. It is also found that the perturbation of the Hubbert's potential is almost equal when the distance in the aquifer from the river is larger than $0.75 \mathrm{~L}$. In other words, this fluctuation reaches the asymptotic value as the distance is larger than $0.75 \mathrm{~L}$.

\section{Vertical Flow Case}

Considering a phreatic aquifer not only with leakage bottom at $z=0$ but with surrounding vertical impervious layers at $\mathrm{x}=0$ and $\mathrm{x}=\mathrm{L}$, the groundwater can therefore move in the vertical direction only, as shown Fig. 3. The source perturbation comes from the head fluctuation at the leakage boundary (at $\mathrm{z}=0$ ).

Thus, the governing equation for this problem can be expressed as:

and the boundary conditions

$$
\frac{\partial}{\partial \mathrm{z}}\left(\mathrm{K} \frac{\partial \mathrm{h}}{\partial \mathrm{z}}\right)=s \frac{\partial \mathrm{h}}{\partial \mathrm{t}}
$$

$$
\mathrm{z}=0, \quad \mathrm{~h}(\mathrm{t})=\mathrm{H}(\mathrm{t}) ; \quad \mathrm{z}=\mathrm{H}, \quad \mathrm{K} \frac{\partial \mathrm{h}}{\partial \mathrm{z}}+\mathrm{n} \frac{\partial \mathrm{h}}{\partial \mathrm{t}}=0
$$

where $\mathrm{n}$ represents the effective porosity at the water table and $\mathrm{s}$ denotes the specific storativity for saturated zone.

Assuming homogeneous soils, $\mathrm{K}=$ constant, and using the same derivative procedure as used for the horizontal flow case, the normalized spectral density function of $h^{1}(x, t), S_{h h} / S_{H H}$, is obtained as:

$$
\begin{aligned}
& \frac{S_{h h}}{S_{H H}}=\frac{\left\{\beta \cos \left[\left(\frac{\bar{\Omega} H}{2}\right)^{1 / 2}\left(\frac{\mathrm{Z}}{\mathrm{H}}-1\right)\right]+\left(\frac{\overline{\Omega_{\mathrm{o}}}}{\mathrm{H}}\right) \sin \left[\left(\frac{\bar{\Omega} \mathrm{H}}{2}\right)^{1 / 2}\left(\frac{\mathrm{Z}}{\mathrm{H}}-1\right)\right]\right\}^{2}+}{\left\{\beta \cos \left[\left(\frac{\bar{\Omega}}{2}\right)^{1 / 2}\right]-\left(\frac{\overline{\Omega_{\mathrm{o}}}}{\underline{\mathrm{H}}}\right) \sin \left[\left(\frac{\bar{\Omega} \mathrm{H}}{2}\right)^{1 / 2}\right\}^{2}+\right.} \\
& \left\{\beta \cosh \left[\left(\frac{\bar{\Omega} \mathrm{H}}{2}\right)^{1 / 2}\left(\frac{\mathrm{Z}}{\mathrm{H}}-1\right)\right]-\left(\frac{\overline{\Omega_{0}}}{\mathrm{H}}\right) \sinh \left[\left(\frac{\bar{\Omega} \mathrm{H}}{2}\right)^{1 / 2}\left(\frac{\mathrm{Z}}{\mathrm{H}}-1\right)\right]\right\}^{2}- \\
& \left\{\beta \cosh \left[\left(\frac{\bar{\Omega} \mathrm{H}}{2}\right)^{1 / 2}\right]+\left(\frac{\Omega_{\mathrm{o}}}{\mathrm{H}}\right) \sinh \left[\left(\frac{\bar{\Omega} \mathrm{H}}{2}\right)^{1 / 2}\right\}^{2}-\right. \\
& \beta^{2}\left\{\sin ^{2}\left[\left(\frac{\bar{\Omega}}{2}\right)^{1 / 2}\left(\frac{\mathrm{Z}}{\mathrm{H}}-1\right)\right]-\sinh ^{2}\left[\left(\frac{\bar{\Omega} \mathrm{H}}{2}\right)^{1 / 2}\left(\frac{\mathrm{Z}}{\mathrm{H}}-1\right)\right]\right\} \\
& \beta^{2}\left\{\sin ^{2}\left[\left(\frac{\bar{\Omega} \mathrm{H}}{2}\right)^{1 / 2}\right]-\sinh ^{2}\left[\left(\frac{\bar{\Omega} \mathrm{H}}{2}\right)^{1 / 2}\right\}\right.
\end{aligned}
$$

where $\bar{\Omega}=\frac{\mathrm{H} \omega \mathrm{S}}{\mathrm{K}}, \overline{\Omega_{\mathrm{o}}}=\frac{\mathrm{H} \omega \mathrm{n}}{\mathrm{K}_{\mathrm{e}}}, \beta=\sqrt{\frac{\omega \mathrm{S}}{2 \mathrm{~K}}}$, and $\mathrm{K}_{\mathrm{e}}$ represents the saturated hydraulic conductivity for unsaturated zone.

It is therefore that we can compare equation (26) to the result of the finite element approximation by assigning values for those input variables. There are two cases we will set up for this comparison. The first case is:

$$
\mathrm{K}=\mathrm{K}_{\mathrm{e}}=10 \mathrm{ft} / \text { year }, \quad \mathrm{s}=0.0001, \quad \mathrm{n}=0.1, \quad \mathrm{H}=100 \mathrm{ft} ; \quad \text { at } \quad \mathrm{z}=0 \mathrm{ft}, \quad \phi_{0}=1.0
$$


Analytical and finite element approximation results for this case are illustrated in Fig. 4 . The quantity of the specific storativity in the aquifer is much less than the one of effective porosity at the free surface. In other words, the effect of the storativity on the fluctuation of the Hubbert's potential can be observed. It is found that the higher the elevation from the bottom of this vertical aquifer, the less the spectral density function of the Hubbert's potential. This behavior is more obvious for the large dimensionless frequency than for the small one. Since the storativity (0.0001) in this phreatic aquifer system is small, the fluctuation of the Hubbert's potential is easily propagated from the bottom of this aquifer to the upper part of it. Then, this fluctuation start to decade when it reaches the free surface due to the high effective porosity, specifically for large frequency. Again, there is an asymptotic behavior of the spectral density function of the Hubbert's potential as the elevation is larger than three quarters of the initial water table $(0.75 \mathrm{H})$.

The input data for the second case is :

$$
\mathrm{K}=\mathrm{K}_{\mathrm{e}}=10 \mathrm{ft} / \text { year, } \mathrm{s}=0.01, \quad \mathrm{n}=0.01, \quad \mathrm{H}=100 \mathrm{ft} ; \quad \text { at } \mathrm{z}=0 \mathrm{ft}, \quad \phi_{0}=1.0
$$

Results for analytical and numerical solutions in this case are shown in Fig. 5. In the second case, the storativity is equal to the effective porosity ( $s=n=0.01$ ). It can be seen that the fluctuation of the Hubbert's potential propagates from the bottom of this aquifer to the upper part of it not so significant as the previous case since the storativity in the later case is much higher than the further case. However, the fluctuation does not decade so fast as the one in the previous case. The asymptotic behavior of the spectral density function of the Hubbert's potential does still exist as the elevation is higher than $0.75 \mathrm{H}$. It is apparent that the finite element approximate has large error as the free surface of water table in the case. This can be recognized as the second case has a small effective porosity so that natural boundary conditions at the free surface become sensitive.

\section{SUMMARY}

The impact of the storativity of phreatic aquifer on the fluctuation of Hubbert's potential was investigated in this study. It was found that the less the storativity is, the easier the fluctuation propagates in the phreatic aquifer. The effective porosity was found to be an important factor for the vertical flow at the free surface of a phreatic aquifer. The smaller the porosity, the higher the fluctuation of the Hubbert's potential. An asymptotic behavior of the spectral density function of the Hubbert's potential can not be found until this fluctuation propagates 0.75 of total distance.

The finite element approximation was applied to simulate the spectral density function of the Hubbert's potential in this study. The result showed that this finite element approximation can predict the behavior of the fluctuation of the Hubbert's potential in the one dimensional subsurface flow very well.

\section{REFERENCES}

1. A. A. Bakr: Stochastic Analysis of the effect of Spatial Variations in hydraulic conductivity on groundwater flow, Ph.D. dissertation, N. Mex. Inst. of Mining and Technol., Socorro,(1976)

2. A. A. Bakr, L. W. Gelhar, A. L. Gutjahr, \& J. R. MacMillan: Stochastic analysis of spatial variability in subsurface flows, 1, Comparison of one- and three- dimensional flows, Water Resources Research, 14(2), 263/271 (1978)

3. J. Bear: Dynamics of Fluids in Porous Media, Elsevier Science, N. Y, (1972)

4. L. W. Gelhar: Stochastic analysis of phreatic aquifers, Water Resources Research, 10(3), 539/545 (1974)

5. L. W. Gelhar: Effects of hydraulic conductivity variations on groundwater flows, in Proceedings, Second International IAHR Symposium on Stochastic Hydraulics, International Association of Hydraulic Research, Lund, Sweden (1976)

6. L. W. Gelhar: Stochastic subsurface hydrology from theory to applications, Water Resources Research, 22(9), 135S/145S (1986)

7. L. W. Gelhar: Stochastic subsurface hydrology, Prentice Hall, N. J. (1993)

8. A. L. Gutjahr, L. W. Gelhar, A. A. Bakr, \& J. R. MacMillan: Stochastic analysis of spatial variability in subsurface flows, 2, Evaluation and application, Water Resources Research, 14(5), 953/959 (1978)

9. P. Marschall \& B. Barczewski: The theory of slug tests in the frequency domain, Water Resources Research, 25(11), 2388/2396 (1989) 


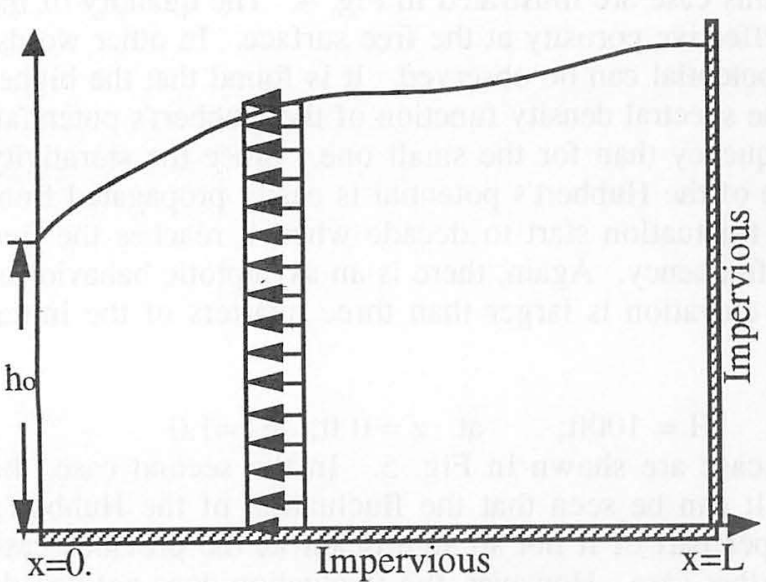

Fig. 1. One-dimensional horizontal phreatic aquifer

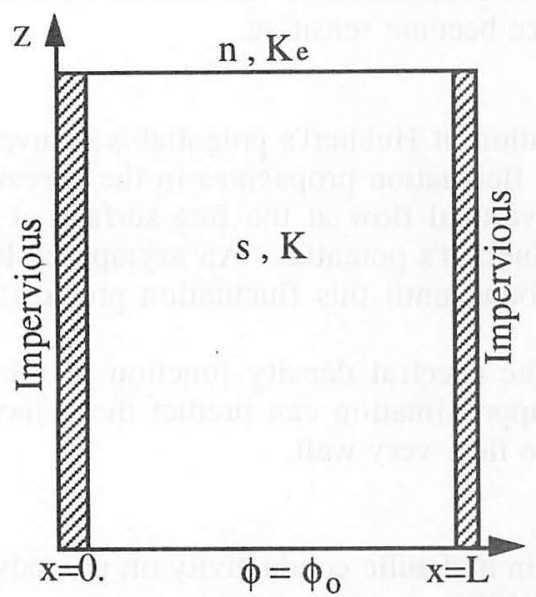

Fig. 3. One dimensional vertical flow case.

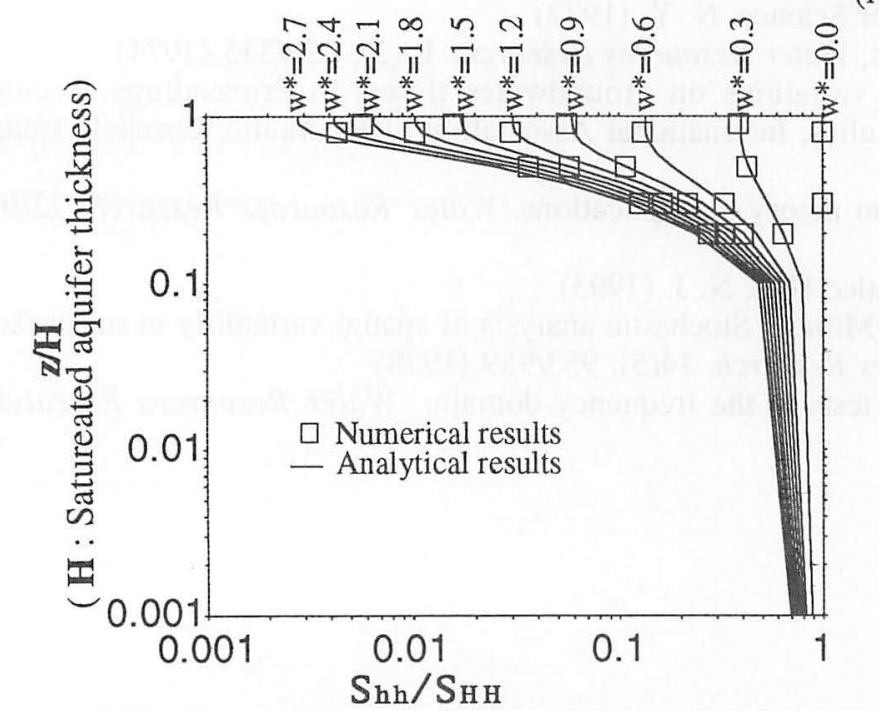

Fig. 5. Solutions of the second case of the vertical flow case. (Note: the $\mathrm{w}^{*}$ is the frequency of pressure fluctuation) 